\title{
Competencias en accesibilidad digital en estudiantes de titulación de maestría sobre e-learning
}

Digital accessibility skills in students of master's course on e-learning

\begin{abstract}
Resumen
La formación de futuros docentes en materia de accesibilidad digital es muy relevante, ya que permite garantizar que personas con discapacidad, mayores y otros colectivos con riesgo de exclusión social, puedan acceder a los procesos educativos mediados por las tecnologías de la información y del conocimiento. Sin embargo, pareciera que no se contempla como parte de la oferta formativa. El objetivo del presente trabajo se centra en identificar los conocimientos en accesibilidad digital de los que parten los alumnos en una titulación de maestría orientada a instruirse como profesionales en el diseño tecnopedagógico de acciones formativas desarrolladas en modalidad e-learning. Para su desarrollo, se ha llevado a cabo un test de autodiagnóstico en accesibilidad digital sobre un grupo de 49 estudiantes de máster. A raíz de los resultados obtenidos, se han orientado los objetivos de la asignatura de accesibilidad contemplada en el máster para potenciar el desarrollo de competencias en esta materia.
\end{abstract}

\section{Palabras clave}

Accesibilidad digital, competencias, inclusión, documentos digitales, e-learning.

\begin{abstract}
The training of future teachers in digital accessibility matter's is very relevant, since it allows guaranteeing that people with disabilities, old people and other groups at risk of social exclusion, can access educational processes though information and knowledge technologies. However, it seems that it is not considered as part of the training offer. The aim of the present work has focused on identifying the knowledge in digital accessibility of the students in a master's course aimed at educating themselves as professionals in the techno-pedagogical design of training actions developed in e-learning mode. For its development, a self-diagnostic test on digital accessibility was carried out on a group of 49 master students. As a result of the obtained results, the objectives of the accessibility subject contemplated in the master have been oriented to promote the development of skills in this matter.
\end{abstract}

\section{Keywords}

Digital accessibility, skills, inclusion, digital documents, e-learning.

\author{
Lourdes González-Perea \\ <lourdes.gonzalez.perea@ui1.es> \\ Universidad Isabel I · Universidad de \\ Málaga. España
}

\section{Almudena Cotán Fernández <almudena.cotan@uca.es> \\ Universidad de Cádiz. España}

\section{Ana Cristina García-Pérez <anacristina.gacria@ui1.es>}

Universidad Isabel I. España

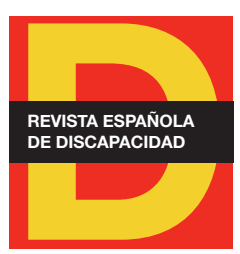

Para citar:

González-Perea, L. et al. (2020).

"Competencias en accesibilidad digital en estudiantes de titulación de maestría sobre e-learning". Revista Española de Discapacidad, 8(2), pp. 129-150.

Doi: <https://doi.org/10.5569/23405104.08.02.06>

Fecha de recepción: 04-07-2019 Fecha de aceptación: 19-08-2020 


\section{Introducción}

En las instituciones de educación superior (ES), el proceso de educación basado en un modelo inclusivo surge con fuerza para defender los derechos del alumnado no tradicional (Everett y Oswald, 2018). La mejora de la igualdad de oportunidades y de prácticas es uno de los principales principios que subyace a estas prácticas (Vlachou y Papanou, 2018).

En la actualidad, existe un importante respaldo legislativo para el alumnado con discapacidad en el contexto universitario. Buena muestra de ello se puede localizar en los avances legislativos que se han alcanzado y que aseguran la igualdad de acceso y permanencia de los estudiantes con discapacidad en estas instituciones. A nivel internacional, cabe destacar la Declaración Universal de Derechos Humanos (Naciones Unidas, 1948), la Convención sobre los Derechos de las Personas con Discapacidad (Naciones Unidas, 2006), la Conferencia Mundial sobre Educación Superior (UNESCO, 1998) y la Estrategia Europa 2020 para un crecimiento inteligente, sostenible e integrador (Comisión Europea, 2010).

En el contexto nacional, esta oleada por realizar mejoras en el sistema universitario llegó en la década de los 80, concretamente con la promulgación, el posterior desarrollo normativo de la Constitución Española de 1978 en su artículo 49 o la ley LISMI (1982). Veinte años más tarde, esta proyección legislativa para asegurar la igualdad de oportunidades y acceso se vio ratificada con la Ley 51/2003, de 2 de diciembre, de igualdad de oportunidades, no discriminación y accesibilidad universal de las personas con discapacidad (LIONDAU), donde se destaca la transversalidad de las políticas y la mejora de la calidad de vida de las personas con discapacidad. En la actualidad, podemos destacar el actual Real Decreto Legislativo 1/2013, de 29 de noviembre, por el que se aprueba el Texto Refundido de la Ley general de derechos de las personas con discapacidad y de su inclusión social, el Real Decreto de Ordenación de las Enseñanzas Universitarias Oficiales (2007), la Ley Orgánica 4/2007, de 12 de abril, de modificación de la Ley Orgánica de Universidades (LOMLOU) o el Real Decreto 1276/2011, de 16 de septiembre, de adaptación normativa a la Convención internacional sobre los derechos de las personas con discapacidad.

Gracias a este tipo de acciones, conseguir la meta de una universidad inclusiva es cada vez un objetivo más tangible. En España, hay aproximadamente 22000 estudiantes con discapacidad en las universidades (Fundación Universia, 2018). Realidad similar en otros contextos internacionales donde la tasa de matriculación y la demanda de acceso es cada vez mayor (Hadjikakou y Hartas, 2008; Sakız y Sarıcal, 2017). Sin embargo, aunque esta realidad viene justificada, en parte, por los importantes avances en materia legislativa para garantizar el acceso y la igualdad de oportunidades de los estudiantes con discapacidad, parece no ser suficiente para asegurar su permanencia (Perera-Rodríguez y Moriña, 2019). Aunque los datos de matriculación se encuentran en auge y aumento, el riesgo de abandono sigue estando muy presente, siendo mucho mayor para el alumnado con discapacidad que para el resto (Garabal, 2015; Nganji et al. 2011; Seale, 2017). Esta realidad, unida a la ausencia de formación de los profesores en materia de discapacidad, planes de estudios inaccesibles, ausencia de ajustes razonables, actitudes negativas de los profesorados, materiales no accesibles o barreras arquitectónicas, evidencian que la universidad sigue siendo una institución excluyente (Moriña et al., 2015; Garabal, 2015; Langørgen y Magnus, 2018; Vlachou y Papananou, 2015). Por tanto, se torna necesario la incorporación de los principios de la educación inclusiva en las políticas y prácticas educativas universitarias, la creación de planes de formación orientados al profesorado y de oficinas de apoyo 
para este colectivo de estudiantes o el uso de las tecnologías de la información y la comunicación (TIC) a través de recursos y aplicaciones informáticas accesibles (Gutiérrez y Restrepo y Martínez, 2010; PereraRodríguez y Moriña, 2019).

Consecuentemente, diversos estudios han evidenciado las múltiples ventajas que tiene el uso de las TIC en los procesos educativos del alumnado (Nganji et al., 2011; Seale et al., 2010; Van Jaarsveldt y NdeyaNdereya, 2015). Tal y como se ratifica en estos trabajos, el uso de métodos digitales en los procesos de aprendizaje genera oportunidades de conocimiento y opciones de participación recreando vivencias de aprendizaje reales (Moriña et al., 2014; Perera-Rodríguez y Moriña, 2019). Sin embargo, si bien es cierto reconocer que estas tecnologías emergentes han facilitado el acceso al conocimiento del alumnado, no menos cierto es que el acceso no se produce en las mismas circunstancias y servicios para todos. Autores como Seale (2006) o Seale et al., (2010) reflejan la falta de accesibilidad digital que presentaba este colectivo de estudiante para acceder al contenido e información. De esta forma, se generan procesos de exclusión y una brecha digital entre el alumnado con discapacidad y el resto de sus compañeros (Ferrer et al., 2011). Sin embargo, tal y como establecen Burgstahler et al. (2004), la accesibilidad debe ser considerada uno de los principios esenciales en el proceso de aprendizaje. En consecuencia, esto permitiría que la mayoría de los estudiantes, con independencia de sus limitaciones personales, sociales o del contexto del navegador, pudieran acceder al contenido digital siendo capaces de comprender, navegar e interactuar con este espacio (Carreras, 2013). De hecho, la accesibilidad digital no sólo beneficia al alumnado con discapacidad sino a todo el colectivo (Gutiérrez y Restrepo y Martínez, 2010).

Numerosos autores centran sus trabajos en analizar el impacto que genera en el alumnado el uso de tecnologías asistidas (Garrison-Wade, 2012; Love et al., 2015; Nganji et al., 2011; Vieiro-lglesias et al., 2015) como son los lectores de pantalla que emplean las personas ciegas o el software de reconocimiento de voz utilizado por personas con discapacidad física, entre otros. Así, "el verdadero desafío de una web inclusiva radica en garantizar un amplio acceso, haciendo que las mismas sean compatibles con tecnologías de asistencia o ayudas técnicas, lo cual es posible si se contemplan los principios básicos de accesibilidad y usabilidad desde la concepción del proyecto de diseño" (Ferrer et al., 2011: 251). Sin embargo, el problema surge cuando el alumnado no puede acceder al contenido, incluso con su producto de apoyo, debido a la incompatibilidad y falta de accesibilidad (Unterfrauner y Weiermair-Märki, 2008). Así, los recursos y los entornos tecnológicos inaccesibles dificultan la participación plena del alumnado (Perera-Rodríguez y Moriña, 2019; Seale et al., 2015). Y, aunque la accesibilidad digital ha de ser uno de los elementos claves y esenciales en el proceso del diseño del aprendizaje (Burgstahler et al., 2004), a tenor de los resultados expuestos, parece no ser así.

Para potenciar la inclusión educativa, dándole un sentido más amplio al colectivo de estudiantes en general, cobra importancia el diseño de los procesos formativos bajo los principios del diseño universal de aprendizaje (DUA) (Ferrer et al., 2011). Cuando las instituciones educativas adoptan este enfoque, tanto los productos como los entornos se diseñan para que sean usados por todas las personas sin necesidad de generar ninguna adaptación o diseño específico (Aparicio y Martínez, 2017; Aparicio y Rodríguez, 2020; Cotán, 2017; Perera-Rodríguez y Moriña, 2019; Preiser y Smith, 2011; Powell, 2013). Consecuentemente, el diseño universal de los productos digitales garantiza que los requisitos establecidos en la accesibilidad (percepción, compresión e interacción) se cumplan (Horton y Leventhal, 2008). Además, se ha ratificado que las modificaciones y ajustes realizados para el alumnado con discapacidad benefician al alumnado en general (HEFCE, 2002; Pliner y Johnson, 2004). 
Por ello, con el propósito de contribuir al conocimiento científico actual y con la finalidad de garantizar que todos los estudiantes puedan acceder a los procesos educativos mediados por las TIC, en la presente investigación se aborda el objetivo de identificar los conocimientos en accesibilidad digital de los que parten los alumnos en un grado de maestría orientado a instruirse como profesionales en el diseño tecnopedagógico de acciones formativas. Todo ello con el fin de establecer una estrategia centrada en potenciar la adquisición de competencias en esta materia en los futuros profesionales del e-learning.

\section{Metodología}

Con el objetivo de poder evaluar la adquisición de competencias en materia de accesibilidad digital en estudiantes de máster orientados a formarse como profesionales del e-learning, se ha aplicado una metodología basada en el análisis documental y en la recogida de valores cuantitativos y cualitativos mediante un cuestionario. En primer lugar, se ha partido del análisis de la oferta existente a nivel de maestría para conocer si se contempla la accesibilidad en los programas formativos que abordan las temáticas de diseño tecnopedagógico y formación para el e-learning. Para ello, se ha procedido a analizar la información disponible en los sitios web en los que se publicitan. A continuación, se ha diseñado un cuestionario online orientado a medir los conocimientos en accesibilidad digital de los que parten los estudiantes que cursan el Máster en diseño tecnopedagógico de la Universidad Isabel I en el que se integra una asignatura de accesibilidad. Por último, a partir de los resultados del cuestionario, se han reorientado los objetivos de la asignatura de accesibilidad del citado máster.

La duración de la presente investigación se ha llevado a cabo durante cinco meses. Concretamente, se ha desarrollado entre los meses de octubre de 2018 y marzo de 2019, contemplándose las siguientes fases:

\section{- Fase I. Inclusión de la accesibilidad en la oferta disponible para profesionalizar la formación me- diada por las TIC}

En primer lugar, se ha realizado un análisis sobre la oferta disponible en España orientada a ofrecer una titulación oficial cuya finalidad sea la formación de expertos en diseño tecnopedagógico en general y en e-learning en particular. Este análisis se ha llevado a cabo en el último trimestre de 2018 (octubrediciembre) sobre la oferta disponible para el curso 2018-2019.

Para la identificación de los títulos relacionados, se han realizado búsquedas en Internet en las que se han combinado las siguientes expresiones: máster, maestría, universidad, universitario, oficial, diseño tecnopedagógico, tecnología educativa, e-learning, etc.

Sobre la oferta identificada, cuyas referencias se recogen en el apéndice, se ha revisado en el sitio web de cada título si existen asignaturas específicas cuya finalidad sea formar a los profesionales en materia de accesibilidad digital.

- Fase II. Medición de los conocimientos de accesibilidad de los que parten los estudiantes de máster 
A continuación, se ha llevado a cabo una experiencia real con estudiantes provenientes de diferentes grados dentro de un máster que reúne estas características (Máster en diseño tecnopedagógico de la Universidad Isabel I) y que ha consistido en identificar el nivel de conocimientos del que parten en materia de accesibilidad sobre los documentos digitales que elaboran. Esta medición se ha realizado sobre la edición del máster, desarrollada durante el curso 2018-2019.

Con tal fin, en enero de 2019, coincidiendo con el inicio de la asignatura de "Usabilidad e Infoaccesibilidad", los estudiantes han cumplimentado un cuestionario online dentro del aula virtual, denominado "Test de autodiagnóstico en accesibilidad digital", que, además de servir para orientar la formación de la asignatura que debían cursar, se ha empleado como medio para provocar sensibilización en el grupo y, por tanto, una mayor predisposición a aprender.

El grupo de estudiantes de la edición 2018-2019 del máster ha estado constituido por 54 alumnos, de los cuales se pueden destacar las siguientes características:

a. Los perfiles de los alumnos son multidisciplinares, con una formación universitaria en distintas áreas de conocimiento (tabla1).

Tabla 1. Titulaciones universitarias de los estudiantes objeto de estudio

\begin{tabular}{|c|c|}
\hline Titulación & $\begin{array}{c}\text { Número de } \\
\text { alumnos }\end{array}$ \\
\hline Administración y Dirección de Empresas & 2 \\
\hline Arquitectura & 2 \\
\hline Biología & 6 \\
\hline Ciencias de la Actividad Física y del Deporte & 2 \\
\hline Ciencias Ambientales & 1 \\
\hline Ciencias del Mar & 1 \\
\hline Estudios Ingleses & 1 \\
\hline Filología (francesa, hispánica e inglesa) & 4 \\
\hline Geología & 1 \\
\hline Historia / Historia de Arte & 5 \\
\hline Humanidades & 1 \\
\hline Ingeniería (montes, Industrial, Informática, Química, Técnica Industrial, Telecomunicación) & 9 \\
\hline Magisterio & 2 \\
\hline Matemáticas & 3 \\
\hline Pedagogía & 2 \\
\hline Periodismo & 1 \\
\hline Primaria & 2 \\
\hline Publicidad y Relaciones Públicas & 1 \\
\hline Química & 3 \\
\hline Relaciones Laborales & 1 \\
\hline Sociología & 1 \\
\hline Traducción e Interpretación & 2 \\
\hline Turismo & 1 \\
\hline
\end{tabular}

Fuente: elaboración propia. 
b. Poseen experiencia profesional, principalmente en el campo docente (Infantil, Primaria, Educación Secundaria, Bachillerato, Formación Profesional Básica y Formación Profesional Inicial).

Para poder identificar los conocimientos de los que parten los estudiantes en materia de accesibilidad digital, el cuestionario diseñado se ha basado en recomendaciones recogidas en los estándares de accesibilidad de referencia internacional (European Telecommunications Standards Institute (ETSI) et al., 2018; W3C, 2018). Además, se ha contado con la validación de dos expertos en accesibilidad TIC con más de diez años de experiencia en este ámbito.

Para facilitar su cumplimentación, se ha preguntado al grupo sobre la aplicación de doce buenas prácticas de accesibilidad sobre los documentos digitales que elaboran, sin ceñirlo a tecnologías concretas, ya que las recomendaciones serían igualmente aplicables en una web que en un texto elaborado con Microsoft Office o LibreOffice. Además, se han incluido dos espacios abiertos al final del cuestionario para recoger la experiencia previa de los estudiantes en la elaboración de documentos digitales en general y en accesibilidad en particular.

El cuestionario comienza con la siguiente afirmación: "Cuando elaboro contenidos digitales (por ejemplo, documentos en Word, presentaciones en PowerPoint o un blog en Internet), de forma general, realizo lo siguiente". A continuación, se introducen las doce buenas prácticas con afirmaciones relacionadas. En cada buena práctica se ofrecen cuatro opciones sobre las que deben elegir una: "Sí", "No", "No sé qué significa" y "No incluyo este recurso en documentos digitales".

Las buenas prácticas contempladas en el cuestionario son:

- Alternativa a las imágenes: "Proporciono una descripción alternativa a las imágenes para quienes no pueden verlas".

- Tamaño de la fuente: "Empleo un tamaño de letra no inferior a 12 puntos para que se vea bien tanto en la pantalla, como impreso".

- Contraste en color: "Aplico adecuadamente los colores para asegurar que existe un buen contraste entre la fuente empleada y el fondo del documento".

- Alternativa a uso semántico del color: "Cuando utilizo el color para transmitir alguna información específica (por ejemplo, un gráfico o tabla de datos en la que marco algunos valores en rojo para distinguirlos de los demás) suelo proporcionar una alternativa para quienes tienen dificultades para distinguir los colores".

- Diseño de las tablas de datos: "Cuando inserto tablas de datos, intento que su estructura sea muy sencilla para que quienes la leen tengan facilidad para relacionar los encabezados 0 categorías con los datos correspondientes. Por ejemplo, no creo celdas combinadas".

- Marcado de encabezados: "Marco una estructura en los contenidos mediante la aplicación de títulos o encabezados de sección para ayudar a delimitar los diferentes bloques del documento (título general, títulos de apartados, etc.)".

- Jerarquía de encabezados: "Respeto los niveles de encabezado para establecer una jerarquía entre los diferentes bloques del documento. Es decir, no utilizo un título de nivel 1 y luego un título de nivel 3".

- Marcado de listas: "Creo listas aplicándoles el estilo o propiedad correspondiente. Es decir, no provoco la apariencia de una lista añadiendo números o guiones al inicio de cada párrafo". 
- Etiquetado de enlaces: "Cuando creo enlaces o hipervínculos, cuido que el texto de estos tenga significado si se lee fuera de contexto. Es decir, no genero enlaces del tipo "Más info" o "Pincha aquí", por ejemplo".

- Formato del documento: "Si quiero separar más los diferentes elementos de un documento (por ejemplo, párrafos, imágenes, etc.) utilizo las propiedades de formato que me ofrece la herramienta. Es decir, no pulso varias veces la tecla "enter" para provocar una mayor separación".

- Subtitulado de contenido audiovisual: "Cuando integro un vídeo que incluye sonido, suelo añadirle subtítulos para que pueda ser entendido por quienes no lo pueden oír o, al menos, aporto una transcripción textual del contenido más relevante".

- Audiodescripción de contenido audiovisual: "Cuando integro un vídeo que incluye imágenes que transmiten información relevante, suelo aportar una descripción mediante la banda de audio para ayudar a las personas ciegas a comprenderlo o, al menos, aporto una transcripción del contenido".

\section{- Fase III. Asimilación de conocimientos sobre accesibilidad digital}

Por último, dentro de la experiencia llevada a cabo con los estudiantes de máster, se ha medido durante la asignatura de "Usabilidad e Infoaccesibilidad" (desarrollada entre enero y marzo de 2019) la capacidad de los futuros profesionales del e-learning para adquirir conocimientos básicos que les permitan potenciar la inclusión educativa mediada por las TIC.

El itinerario formativo cursado por los estudiantes dentro de la asignatura de "Usabilidad e Infoaccesibilidad" se compone de seis unidades didácticas orientadas principalmente a que puedan aprender a producir contenidos usables y accesibles en diferentes formatos. Al inicio de la asignatura (unidad 1) se dan a conocer las necesidades de las personas con discapacidad, mayores y otros colectivos vulnerables en el acceso a la información digital, así como los productos de apoyo que existen para cubrir sus necesidades básicas. A continuación (unidad 2), se muestran las normas técnicas o estándares que se deben tener en cuenta para ofrecer entornos educativos inclusivos. Después (unidades 3 a 5) se trabaja sobre documentos en diferentes formatos para que puedan ir aplicando las técnicas de usabilidad y accesibilidad, comenzando con herramientas de uso más generalizado, como los procesadores de texto y las presentaciones digitales, para finalizar con la elaboración de contenidos para la web. Por último (unidad 6), se aporta un repaso de todas las técnicas a tener en cuenta para producir documentos inclusivos, con independencia de la herramienta con la que se elaboran, y también pautas para potenciar la inclusión mediante la práctica profesional.

Puesto que la asignatura de "Usabilidad e Infoaccesibilidad" ha de impartirse durante tres meses y el test de autodiagnóstico se debía realizar al inicio de esta, los contenidos debían estar previamente elaborados. No obstante, la docente de la asignatura es una persona con discapacidad que lleva trabajando en accesibilidad durante quince años, por lo que conoce ampliamente las técnicas que han de contemplarse para elaborar documentos digitales accesibles. Además, el entorno virtual en el que se imparte el máster es flexible para poder modificar las actividades, incluir referencias adicionales que permitan profundizar en aspectos que se consideren de interés para el grupo, etc. Por tanto, aun habiéndose elaborado los contenidos didácticos con antelación, los resultados del cuestionario servirían para planificar las actividades de evaluación a lo largo de la asignatura, permitiendo a la docente la evaluación de los aspectos más desconocidos por los estudiantes según los resultados del test. 


\section{Resultados}

Los resultados reflejados en este artículo versan sobre tres grupos. En primer lugar, se mostrará el grado de integración de la accesibilidad en la oferta disponible en España orientada a formar a profesionales del e-learning. En un segundo momento, se pasará a detallar la experiencia desarrollada en un aula de titulación de máster con el objetivo de identificar el nivel de conocimientos del que parten los estudiantes de grado en materia de accesibilidad digital. Para finalizar, en tercer lugar, se analizará su capacidad para adquirir una serie de competencias básicas que permitan potenciar la inclusión educativa mediada por las TIC.

\subsection{Inclusión de la accesibilidad en la oferta disponible para profesionalizar la formación mediada por las TIC}

Teniendo en cuenta todas las posibilidades que ofrecen las TIC, como la educación online, es de suma importancia poder diseñar un entorno de aprendizaje que contemple la diversidad humana y no genere exclusión social.

Los nuevos desarrollos tecnológicos facilitan la incorporación social de colectivos excluidos (García Pérez y Ortega Sánchez, 2010), por ello se hace cada vez más necesario la formación de profesionales del e-learning que puedan diseñar soluciones educativas que respondan a los retos de la accesibilidad universal (Alonso, 2007), que facilite, no solo el acceso a través del uso de distintas herramientas y recursos tecnológicos, sino también de los contenidos a través de un diseño tecnopedagógico inclusivo (González y Farnós, 2009). En España se ofertan algunos títulos de máster, propios y oficiales, dirigidos a formar profesionales en el campo del e-learning y la tecnología educativa. En lo que respecta al curso 2018-2019, la oferta se resume en la siguiente tabla (tabla 2).

\begin{tabular}{l}
\hline Tabla 2. Titulaciones ofertadas en España en e-learning y tecnología educativa \\
\begin{tabular}{|l|l|}
\hline Universidad & Titulación \\
\hline Universidad de Nebrija & $\begin{array}{l}\text { Máster en Tecnologías de la Información y la Comunicación para la Educación y } \\
\text { Aprendizaje Digital }\end{array}$ \\
\hline Universidad Católica de Valencia & Máster Universitario en Innovación Tecnológica en Educación \\
\hline Universidad Internacional de Valencia & Máster Universitario en Educación, Tecnologías e Innovación \\
\hline Universidad Internacional de la Rioja & Máster Universitario en E-learning y Redes Sociales \\
\hline Universidad de Salamanca & $\begin{array}{l}\text { Máster Universitario en Las TICs en Educación: análisis y diseño de procesos, } \\
\text { recursos y prácticas formativas }\end{array}$ \\
\hline Universidad a Distancia de Madrid & Máster Universitario en Tecnología Educativa \\
\hline Universidad de la Laguna & Máster Universitario en Educación y Tecnología de la Información y Comunicación \\
\hline Universidad Autónoma de Madrid & $\begin{array}{l}\text { Máster Universitario en Tecnologías de la Información y la Comunicación en } \\
\text { Educación y Formación }\end{array}$ \\
\hline Universitat Oberta de Catalunya & Máster Universitario Educación y TIC (e-learning) \\
\hline Universidad del País Vasco & Máster Universitario en Tecnología, Aprendizaje y Educación \\
\hline
\end{tabular}
\end{tabular}




\begin{tabular}{|l|l|}
\hline Universidad & Titulación \\
\hline Universidad Isabel I & Máster en Diseño Tecnopedagógico (e-learning) \\
\hline Universidad de Extremadura & Máster Universitario en Educación digital \\
\hline Universidad de Barcelona & $\begin{array}{l}\text { Máster de entornos de enseñanza y aprendizaje mediados por tecnologías } \\
\text { digitales }\end{array}$ \\
\hline $\begin{array}{l}\text { Universidad de Sevilla } \\
\text { Universitat Rovira i Virgili } \\
\text { Universitat de les Illes Balears } \\
\begin{array}{l}\text { Universitat de Lleida } \\
\text { Universidad de Murcia }\end{array}\end{array}$ & $\begin{array}{l}\text { Máster e-learning: nuevas tecnologías para el aprendizaje a través de Internet } \\
\text { Conocimiento }\end{array}$ \\
\hline
\end{tabular}

Fuente: elaboración propia.

Tras realizar una revisión de la información que ofrecen de la titulación a través de su página web, sobre el plan de estudios y guías docentes, pareciera que la mayoría no incorpora el desarrollo de competencias dirigidas al conocimiento y aplicación de la accesibilidad en entornos formativos.

De las 15 titulaciones presentadas en la tabla anterior, solamente se han ubicado dos que incluyen en su plan de estudios una asignatura para desarrollar competencias específicas en esta área (tabla 3).

\begin{tabular}{l}
\hline Tabla 3. Titulaciones que incorporan en su plan de estudios competencias en accesibilidad \\
\begin{tabular}{|l|l|l|}
\hline Universidad & Titulación & Asignatura \\
\hline Universidad Internacional de La Rioja & $\begin{array}{l}\text { Máster Universitario en E-learning y Redes } \\
\text { Sociales }\end{array}$ & Usabilidad y Accesibilidad online \\
\hline Universidad Isabel I & $\begin{array}{l}\text { Máster en Diseño Tecnopedagógico } \\
\text { (e-learning) }\end{array}$ & Usabilidad e Infoaccesibilidad \\
\hline
\end{tabular}
\end{tabular}

Fuente: elaboración propia.

De acuerdo a lo anterior, se puede evidenciar que, en lo que respecta a la oferta formativa analizada, la accesibilidad de las TIC es un campo poco relevante dentro de la formación de profesionales del e-learning.

\subsection{Medición de los conocimientos de accesibilidad de los que parten los estudiantes de grado}

Para identificar los conocimientos con los que cuentan los titulados de grado en materia de accesibilidad digital se ha empleado el "Test autodiagnóstico en accesibilidad digital" que ha sido cumplimentado por los estudiantes de uno de los títulos en diseño tecnopedagógico que cuenta con una asignatura específica sobre accesibilidad.

El cuestionario ha sido cumplimentado por 49 de los 54 estudiantes que cursaban el máster $(90,7 \%$ del aula), obteniéndose los siguientes resultados: 
- Alternativa a las imágenes: "Proporciono una descripción alternativa a las imágenes para quienes no pueden verlas".

Ante esta afirmación, un $20 \%$ de los participantes declara incluir alternativas textuales, mientras que un $76 \%$ no lo contempla. Un $2 \%$ no sabe qué significa y un $2 \%$ no trabaja con imágenes.

- Tamaño de la fuente: "Empleo un tamaño de letra no inferior a 12 puntos para que se vea bien tanto en la pantalla, como impreso".

Un $96 \%$ de los participantes utiliza un tamaño de fuente adecuado en sus documentos, mientras que un $4 \%$ no lo hace.

- Contraste en color: "Aplico adecuadamente los colores para asegurar que existe un buen contraste entre la fuente empleada y el fondo del documento".

Un $90 \%$ del grupo cuida el contraste entre la fuente y el fondo que emplea, mientras que un $10 \%$ no lo contempla.

- Alternativa a uso semántico del color: "Cuando utilizo el color para transmitir alguna información específica (por ejemplo, un gráfico o tabla de datos en la que marco algunos valores en rojo para distinguirlos de los demás) suelo proporcionar una alternativa para quienes tienen dificultades para distinguir los colores".

Sólo un $14 \%$ del grupo aplica una alternativa accesible al uso semántico del color. El $86 \%$ del aula no lo contempla.

- Diseño de las tablas de datos: "Cuando inserto tablas de datos, intento que su estructura sea muy sencilla para que quienes la leen tengan facilidad para relacionar los encabezados o categorías con los datos correspondientes. Por ejemplo, no creo celdas combinadas".

Un $65 \%$ de los participantes declara diseñar adecuadamente las tablas de datos, mientras que un $33 \%$ no lo hace. Un $2 \%$ no comprendió en qué consiste la buena práctica.

- Marcado de encabezados: "Marco una estructura en los contenidos mediante la aplicación de títulos o encabezados de sección para ayudar a delimitar los diferentes bloques del documento (título general, títulos de apartados, etc.)".

Un $98 \%$ de los participantes indica que aplica a encabezados a los documentos. El $2 \%$ restante no comprendió el enunciado de la buena práctica.

- Jerarquía de encabezados: "Respeto los niveles de encabezado para establecer una jerarquía entre los diferentes bloques del documento. Es decir, no utilizo un título de nivel 1 y luego un título de nivel 3". Un $86 \%$ respeta la jerarquía de los encabezados, mientras que un $4 \%$ no lo hace. El $10 \%$ restante no sabe qué significa.

- Marcado de listas: "Creo listas aplicándoles el estilo o propiedad correspondiente. Es decir, no provoco la apariencia de una lista añadiendo números o guiones al inicio de cada párrafo".

Un $53 \%$ declara crear adecuadamente las listas, mientras que un $27 \%$ indica que no lo hace. Un $20 \%$ del grupo no sabe qué significa.

- Etiquetado de enlaces: "Cuando creo enlaces o hipervínculos, cuido que el texto de éstos tenga significado si se lee fuera de contexto. Es decir, no genero enlaces del tipo "Más info" o "Pincha aquí", por ejemplo". 
Un 51\% declara etiquetar adecuadamente los enlaces, mientras que un $43 \%$ no lo hace. Un $4 \%$ no sabe qué significa y un $2 \%$ no emplea este recurso.

- Formato del documento: "Si quiero separar más los diferentes elementos de un documento (por ejemplo, párrafos, imágenes, etc.) utilizo las propiedades de formato que me ofrece la herramienta. Es decir, no pulso varias veces la tecla "enter" para provocar una mayor separación".

Un $57 \%$ del grupo considera que utiliza las opciones de formato que les ofrecen los sistemas de gestión de contenidos (CMS), mientras que un 43 \% utiliza el retorno de carro para provocar mayor separación entre los elementos de los documentos que producen.

- Subtitulado de contenido audiovisual: "Cuando integro un vídeo que incluye sonido, suelo añadirle subtítulos para que pueda ser entendido por quienes no lo pueden oír o, al menos, aporto una transcripción textual del contenido más relevante".

Un $14 \%$ de los participantes incluye subtítulos en los vídeos o, en su defecto, ofrece una transcripción del contenido sonoro, mientras que un $78 \%$ no lo contempla. El $8 \%$ restante no trabaja con contenido audiovisual.

- Audiodescripción de contenido audiovisual: "Cuando integro un vídeo que incluye imágenes que transmiten información relevante, suelo aportar una descripción mediante la banda de audio para ayudar a las personas ciegas a comprenderlo o, al menos, aporto una transcripción del contenido".

Un $4 \%$ de los participantes incluye audiodescripción en los vídeos o, en su defecto, ofrece una transcripción del contenido visual, mientras que un $86 \%$ no lo contempla. Un $2 \%$ del grupo no sabe qué significa y un $8 \%$ no trabaja con contenido audiovisual.

A continuación, se ofrece una síntesis de los resultados obtenidos (tabla 4):

\begin{tabular}{|c|c|c|c|c|}
\hline Buena práctica & Sí & No & No saben & No aplica \\
\hline Alternativa a las imágenes & $20 \%$ & $76 \%$ & $2 \%$ & $2 \%$ \\
\hline Tamaño de la fuente & $96 \%$ & $4 \%$ & $2 \%$ & $2 \%$ \\
\hline Contraste en color & $90 \%$ & $10 \%$ & $0 \%$ & $0 \%$ \\
\hline Alternativa a uso semántico del color & $14 \%$ & $86 \%$ & $0 \%$ & $0 \%$ \\
\hline Diseño de tablas de datos & $65 \%$ & $33 \%$ & $2 \%$ & $0 \%$ \\
\hline Marcado de encabezados & $98 \%$ & $0 \%$ & $2 \%$ & $0 \%$ \\
\hline Jerarquía de encabezados & $86 \%$ & $4 \%$ & $10 \%$ & $0 \%$ \\
\hline Marcado de listas & $53 \%$ & $27 \%$ & $20 \%$ & $0 \%$ \\
\hline Etiquetado de enlaces & $51 \%$ & $43 \%$ & $4 \%$ & $2 \%$ \\
\hline Formato del documento & $57 \%$ & $43 \%$ & $0 \%$ & $0 \%$ \\
\hline Subtitulado de contenido audiovisual & $14 \%$ & $78 \%$ & $0 \%$ & $8 \%$ \\
\hline Audiodescripción de contenido audiovisual & $4 \%$ & $86 \%$ & $2 \%$ & $8 \%$ \\
\hline
\end{tabular}

Fuente: elaboración propia. 
Por último, de las preguntas abiertas contempladas al final del cuestionario para conocer el grado de experiencia de los participantes en la elaboración de documentos digitales en general y en accesibilidad en particular, se puede extraer lo siguiente:

- Los participantes principalmente emplean los documentos digitales para elaborar textos con Microsoft Word y presentaciones en PowerPoint. Algunos de ellos exportan los documentos que elaboran a formato PDF. Un grupo muy reducido de los participantes elaboran contenidos para la Web (HTML).

- El grupo declara que no posee experiencia ni formación previa en accesibilidad digital (sólo existen casos puntuales, principalmente provenientes de grados de ingeniería). Algunos de los participantes han contado en el aula con estudiantes con discapacidad, encargándose de realizarles adaptaciones curriculares.

\subsection{Adquisición de conocimientos sobre accesibilidad digital}

Partiendo de los resultados del cuestionario online cumplimentado por los estudiantes, se compartió con el grupo a través del aula virtual las principales conclusiones del test de autodiagnóstico y se adaptaron los objetivos de la asignatura para poder profundizar durante su desarrollo en las carencias detectadas. La información compartida con los estudiantes fue la siguiente:

- Imágenes: un $76 \%$ de los participantes indicó que no describe las imágenes de los documentos que elaboran. Se propone profundizar a lo largo de la asignatura en cómo describir las imágenes, permitiendo al estudiante distinguir previamente si requieren o no de descripción.

- Fuente: un $96 \%$ de los estudiantes confirmó que emplea un tamaño adecuado en la letra y un $90 \%$ que cuida el contraste. Por tanto, el grupo considera que dispone de conocimientos básicos en estas buenas prácticas. No obstante, se les mostrará cómo pueden emplear una herramienta para analizar el contraste.

- Alternativa a uso semántico del color: un $86 \%$ declaró no contemplar una alternativa al uso del color para transmitir información. Se les propone incidir en esta cuestión a lo largo de la asignatura.

- Diseño de tablas de datos: un $65 \%$ indicó que diseña las tablas adecuadamente, pero hay parte del grupo que no lo hace. Puesto que la construcción de tablas de datos accesibles es una tarea compleja, se propone profundizar en las técnicas para su diseño a lo largo de la asignatura.

- Estructura de encabezados: un $96 \%$ indicó que utiliza los títulos para marcar una estructura adecuadamente, pero esta cifra baja al $86 \%$ cuando se pregunta si se respeta la jerarquía en su uso. Se les propone revisar las técnicas para aplicar los títulos correctamente.

- Listas: un $53 \%$ de los participantes indicó que crea las listas aplicándoles la propiedad correspondiente, pero gran parte del grupo reconoció no hacerlo, por lo que, de igual modo, se les propone revisar las técnicas.

- Enlaces: un $51 \%$ de los participantes consideró que aporta títulos representativos a los enlaces, pero gran parte del grupo reconoció que no lo hace adecuadamente. El grupo aprenderá a etiquetar los vínculos de forma adecuada.

- Formato: un $57 \%$ indicó que no separan los elementos de un documento pulsando la tecla enter o el espacio. No obstante, parte del grupo advirtió que aplica estos métodos. Los estudiantes aprenderán a modificar el formato sin recurrir a estas malas prácticas. 
- Vídeos: un $86 \%$ de los participantes reconoció no aplicar audiodescripción y un $78 \%$ no contemplar subtitulado o, en su defecto, una transcripción. Además, un $8 \%$ del grupo indicó que no trabaja con contenido audiovisual. Se propone profundizar en las técnicas para que el contenido audiovisual que generen o utilicen sea más accesible.

Mediante las actividades rediseñadas por la docente tras el resultado del cuestionario de autodiagnóstico, el grupo desarrolló un debate sobre inclusión educativa mediada por las TIC, la elaboración de 3 documentos usables y accesibles en diferentes formatos (Microsoft Word, PowerPoint y HTML) y la cumplimentación de un cuestionario con preguntas tipo test en el que los estudiantes debían decidir cómo dar respuesta a diferentes barreras de accesibilidad que pueden presentarse en documentos digitales.

El debate se empleó para generar conciencia en el grupo en cuanto a la necesidad de involucrar a toda la sociedad en la eliminación de barreras de accesibilidad. Una estrategia para la generación de conciencia fue el test de autodiagnóstico, sobre el que muchos estudiantes indicaron durante el desarrollo del debate que les había supuesto una herramienta de reflexión al darse cuenta de que estaban generando documentos digitales inaccesibles.

La elaboración de los documentos en diferentes formatos permitió constatar que el grupo aplicaba adecuadamente un volumen importante de buenas prácticas de usabilidad y accesibilidad, pero otras no siempre eran capaces de resolverlas. A este respecto, se deben destacar los siguientes resultados asociados a la corrección de las actividades:

- El grupo mostró dificultades para aplicar adecuadamente los colores, pero con el avance en la asignatura este aspecto fue mejorando. De forma general, todos los estudiantes aprendieron a generar buen contraste entre fuente y fondo y a proporcionar una alternativa textual cuando se empleaba el color con fines informativos.

- Bastantes estudiantes utilizaron el retorno de carro para separar los elementos de los documentos, aun habiéndose aportado pautas para recurrir a las propiedades de formato. Por tanto, se trata de un requisito de accesibilidad que requiere de un mayor esfuerzo para comprender su importancia y aplicarlo.

- Los estudiantes aprendieron a aplicar una estructura de encabezados en los documentos digitales que generaron, pero cuando incluían una portada, el título no lo integraban en tal estructura, generando así una barrera de accesibilidad al inicio de los contenidos.

- Los estudiantes aprendieron a describir las imágenes, aunque en muchas ocasiones ofrecían descripciones demasiado detalladas y en otras dejaban sin informar de aspectos relevantes. Se detecta que resulta dificultoso comprender qué información puede ser importante para quienes no ven las imágenes.

- Los estudiantes mostraron cierta reticencia para enfrentarse a la generación de contenido accesible en HTML, aunque tras finalizar la práctica, valoraron de forma muy positiva la actividad además de útil para su desarrollo profesional en el entorno del e-learning.

Por último, en el cuestionario con preguntas tipo test cumplimentado por el grupo en la última unidad didáctica de la asignatura, se pudo ver cómo los estudiantes desarrollaron la capacidad de aportar soluciones a las malas prácticas que habían identificado mediante el autodiagnóstico, obteniéndose una calificación media de 8,82 sobre 10 . 
El cuestionario estaba constituido por 20 preguntas en las que se recogían cuestiones relacionadas con las 12 buenas prácticas contempladas en el autodiagnóstico. No obstante, la aplicación de las buenas prácticas en este cuestionario final se relacionaron con técnicas específicas y, en muchos casos, con formatos de documentos. A continuación, se ofrecen dos ejemplos de preguntas integradas en el cuestionario final:

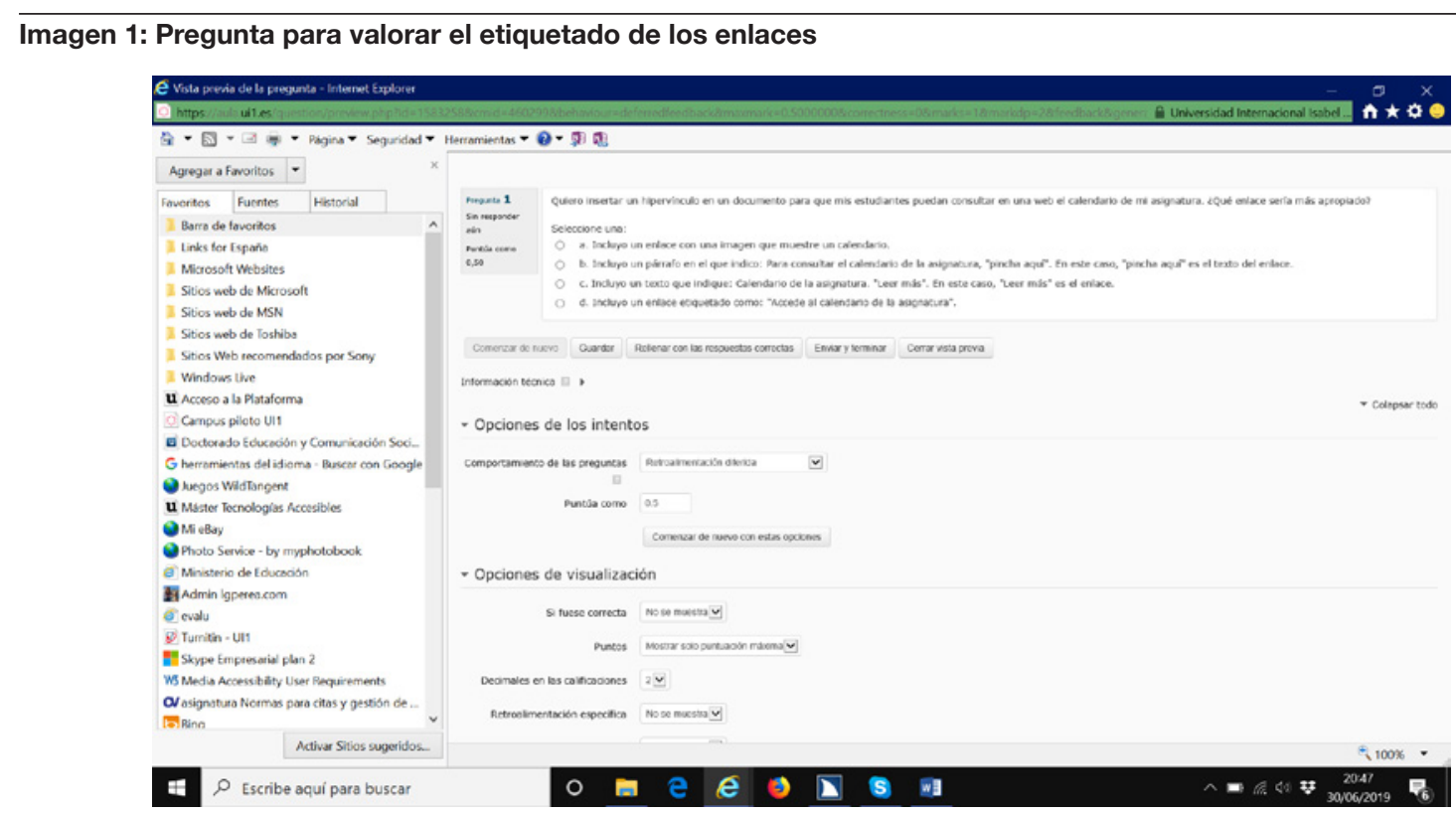

Fuente: elaboración propia.

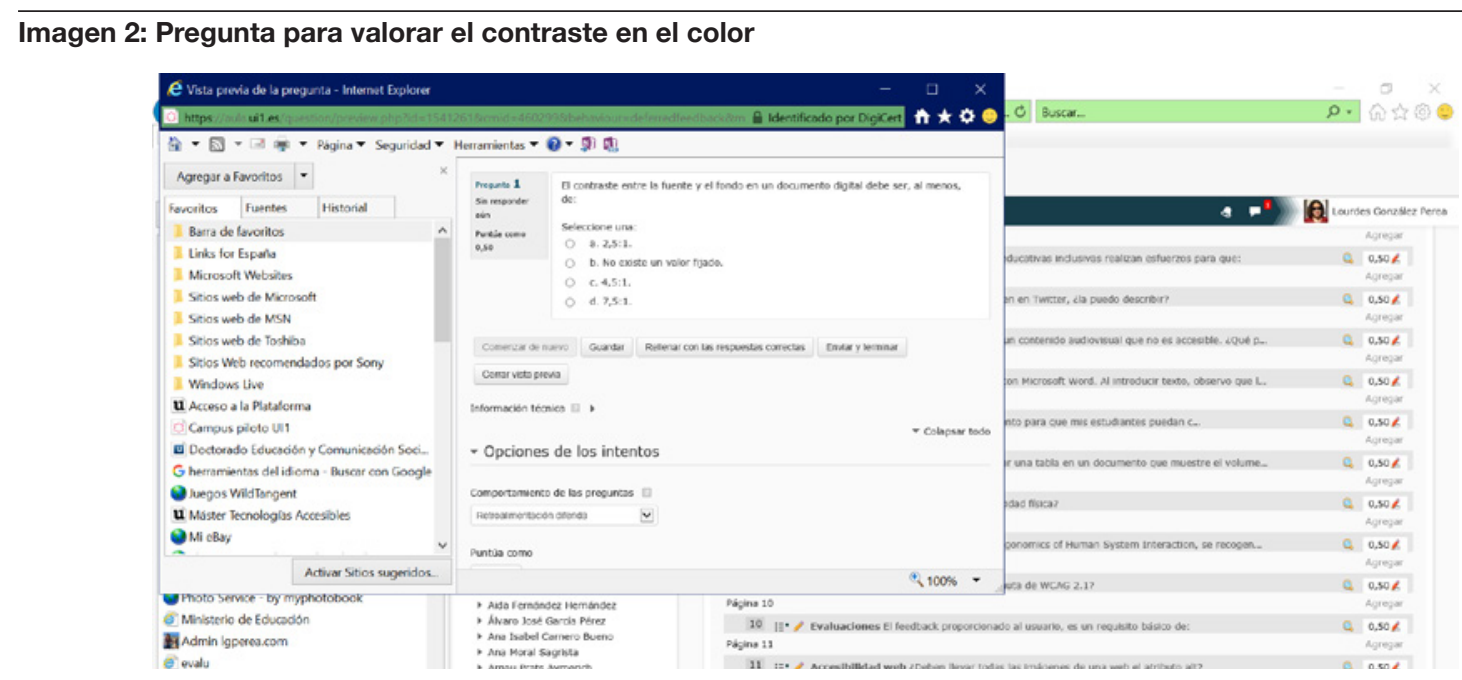

Fuente: elaboración propia. 


\section{Discusión}

Las instituciones educativas han de velar por el desarrollo de modelos inclusivos (Everett y Oswald, 2018; Moriña, 2018). Todo ello realizado bajo los principios de igualdad de oportunidades y accesibilidad universal (Aparicio y Rodríguez, 2020; Vlachou y Papanou, 2018). Y, pese a que existe un importante respaldo legislativo, así como normativa específica y técnica en materia de accesibilidad, parece no ser suficiente.

Los resultados reflejados en este trabajo evidencian que la formación de los futuros docentes en materia de accesibilidad digital es un elemento esencial para el correcto desarrollo de prácticas inclusivas en el aula (Alonso, 2007; Burgstahler et al., 2004; Moriña et al., 2015). Autores como Aparicio y Martínez (2017), Aparicio y Rodríguez (2020), García Pérez y Ortega Sánchez (2010) y González y Farnós (2009), ponen de manifiesto que el desarrollo de procesos tecnológicos adaptados a los principios de accesibilidad universal estimula y fomenta la inclusión. Consecuentemente, en este trabajo se apoyan los resultados obtenidos por Perera-Rodríguez y Moriña (2019), al afirmar que es necesario la creación de planes de formación orientados al profesorado que se basen el uso de las TIC a través de recursos y aplicaciones informáticas accesibles. Tal y como se propone en el DUA, los entornos educativos han de ser elaborados y diseñados para que sean usados por todas las personas sin necesidad de realizar ajustes posteriores o diseños específicos (Cotán, 2017; Horton y Leventahl, 2008; Preiser y Smith, 2011; Powell, 2013).

Sin embargo, los resultados obtenidos evidencian que las titulaciones, oficiales y no oficiales, encaminadas a formar a los futuros expertos en diseño tecnopedagógico, no contemplan la accesibilidad digital entre su propuesta formativa. Estos resultados son contraproducentes con la idea aquí propuesta: la formación de los docentes en materia de atención a la discapacidad y accesibilidad digital es esencial para el desarrollo de prácticas inclusivas en las aulas. Por tanto, el desarrollo de estos procesos apoyados en métodos de aprendizaje permitirá que el estudiante vivencie oportunidades de aprendizaje reales (Moriña et al., 2014; Perera-Rodríguez y Moriña, 2019) evitando, de esta forma, la tan temida brecha digital entre el alumnado con y sin discapacidad (Seale, 2006; Seale et al. , 2010). De hecho, estudios como los de Ferrer et al. (2011) consideran que tanto la usabilidad como la accesibilidad son factores esenciales para superar la brecha digital. Esto potenciaría y permitiría la inclusión social y digital de todo el colectivo de alumnado. Sin embargo, aunque la accesibilidad ha de ser uno de los principales elementos a tener en cuenta en el diseño de aprendizaje (Burgstahler et al., 2004), con los resultados aquí expuestos, parece que no es así.

Muchos de los estudiantes de este trabajo muestran una buena predisposición a realizar estos ajustes, aun sin recibir formación previa. Sin embargo, su formación en materia de accesibilidad se ha reflejado como escasa y casi inexistente. De forma paralela, se ha ratificado que es un aspecto esencial para su correcta implementación. Así, tras recibir formación en esta materia, los futuros profesionales realizan los ajustes razonables para que algunos colectivos situados en una posición de vulnerabilidad, como es el caso del alumnado con discapacidad, puedan acceder al contenido. Sin embargo, aunque se reciba formación avanzada en materia de accesibilidad digital, los procesos de sensibilización, actitudes positivas y empatía son necesarios en todo este proceso (Garabal, 2015). Resultados similares se hallaron en otros trabajos enfocados a la formación docente en materia de discapacidad en el ámbito universitario (Langørgen y Magnus, 2018; Moriña, 2018; Van Jaarsveldt y Ndeya-Ndereya, 2015). 
En este aspecto, se puede finalizar afirmando que la formación y aplicación de los principios de accesibilidad universal no sólo corresponde a los profesionales del ámbito educativo sino a todos los colectivos y áreas sociales. De esta forma, se evitará la producción de recursos y entornos tecnológicos inaccesibles que dificulten la plena participación de las personas con discapacidad (Perera-Rodríguez y Moriña, 2019; Seale et al., 2015).

\section{Conclusiones}

Una vez conocida la oferta formativa disponible en España para el desarrollo de competencias relacionadas con el diseño tecnopedagógico orientado a potenciar la educación mediada por las TIC, y tras llevar a cabo una experiencia dentro de un aula virtual con estudiantes de máster especializado en formación en modalidad e-learning, se pueden establecer las siguientes conclusiones relacionadas con la adquisición de conocimientos básicos sobre accesibilidad digital:

- En la amplia oferta formativa identificada a nivel de titulación de máster para adquirir competencias en diseño tecnopedagógico en general y aplicable al e-learning en particular, apenas se han localizado dos casos en los que se contemple una asignatura específica sobre accesibilidad digital.

- Las personas que estudian una titulación de grado en la universidad en España no culminan este proceso con conocimientos básicos sobre accesibilidad a las TIC, como se puede deducir de los resultados de un test de autodiagnóstico en accesibilidad digital cumplimentado por 49 estudiantes de máster con estudios de grado de diferentes disciplinas. No obstante, los titulados superiores finalizan sus estudios con competencias en la producción de contenidos digitales en diferentes formatos, aunque durante su formación no hayan recibido pautas concretas relacionadas con la accesibilidad de contenidos para personas con discapacidad, mayores y otros colectivos con riesgo de exclusión social.

- Existen normas técnicas (estándares) de referencia internacional en las que se contemplan las pautas aplicables a la producción de documentos digitales para conseguir que sean accesibles. Estos documentos han de emplearse como base en el desarrollo de materias orientadas a la producción de contenido digital.

- Los estudiantes con conocimientos básicos en producción de contenidos digitales aplican algunas buenas prácticas en accesibilidad, aun no habiendo recibido formación específica al respecto. Por ejemplo, emplean tamaños de fuente adecuados y cuidan que exista contraste entre la letra utilizada y el fondo del documento.

- Las personas que deban producir contenidos digitales requieren de formación en accesibilidad para poder aplicar los requisitos que posibilitan que personas con discapacidad, mayores y otros colectivos vulnerables puedan acceder a la información. Por ejemplo, la alternativa a las imágenes, el diseño de tablas accesibles y el marcado de estructura en un documento implica disponer de conocimientos avanzados en accesibilidad.

- Aun recibiendo formación avanzada en materia de accesibilidad digital, la aplicación adecuada de algunos requisitos depende de un proceso complejo de empatía y conocimiento de las necesidades 
específicas de diferentes colectivos. Por ejemplo, resulta complicado aportar una correcta descripción a una imagen que disponga de una alta carga informativa o audiodescribir un vídeo para que sea comprendido por personas ciegas.

- Los docentes han de adquirir conocimientos en accesibilidad, además de para producir contenidos digitales accesibles, para transmitir estos conocimientos a los profesionales del futuro, con independencia a la disciplina en la que desarrollan su trayectoria profesional. La inclusión social y la accesibilidad corresponden a necesidades consideradas transversales para avanzar a nivel social. 


\section{Referencias bibliográficas}

Alonso, F. (2007). "Algo más que suprimir barreras: conceptos y argumentos para una accesibilidad universal". TRANS: revista de traductología, 11, pp. 15-30. DOI: https://doi.org/10.24310/TRANS.2007.v0i11.3095.

Aparicio, M. y Martínez, E. (2017). "Accesibilidad universal: sentido normativo e implicaciones en la educación y la práctica profesional”. Revista Española de Discapacidad, 5(l), pp. 25-41. DOI: https://doi.org/10.5569/23405104.05.01.02.

Aparicio, M. y Rodríguez, S. (2020). "Ética, trabajo social y derecho a la accesibilidad". Revista Española de Discapacidad, 8(I), pp. 25-41. DOI: https://doi.org/10.5569/2340-5104.08.01.02.

Burgstahler, S. et al. (2004). "Making distance learning courses accessible to students and instructors with disabilities: A case study". The Internet and higher education, 7(3), pp. 233-246. DOI: https://doi.org/10.1016/j. iheduc.2004.06.004.

Carreras, O. (2013). Accesibilidad web y SEO. Recuperado de https://www.usableyaccesible.com/archivos/Accesibilidad_web_y_SEO_capitulo_ampliado_olga_carreras.pdf.

Comisión Europea (2010). Europa 2020. Una estrategia para un crecimiento inteligente, sostenible e integrador. Recuperado de https://eur-lex.europa.eu/legal-content/ES/TXT/?uri=celex:52010DC2020.

Cotán, A. (2017). "Educación inclusiva en las instituciones de educación superior: narrativas de estudiantes con discapacidad". Revista Española de Discapacidad, 5(I), pp. 43-61. DOI: https://doi.org/10.5569/23405104.05.01.03.

España. Constitución Española. Boletín Oficial del Estado, 29 de diciembre de 1978, núm. 311, pp. 29313-29424.

España. Ley 13/1982, de 7 de abril, Integración social de los minusválidos. Boletín Oficial del Estado, 30 de abril de 1982, núm. 103, pp. 11106-11112.

España. Ley 51/2003, de 3 de diciembre, de igualdad de oportunidades, no discriminación y accesibilidad universal de las personas con discapacidad. Boletín Oficial del Estado, 4 de diciembre del 2003, núm. 289, pp. 43187-43195.

España. Ley Orgánica 4/2007, de 12 de abril, por la que se modifica la Ley Orgánica 6/2001, de 21 de diciembre, de Universidades. Boletín Oficial del Estado, 13 de abril de 2007, núm. 89, pp. 16241-16260.

España. Real Decreto 1276/2011, de 16 de septiembre, de adaptación normativa a la Convención Internacional sobre los derechos de las personas con discapacidad. Boletín Oficial del Estado, 17 de septiembre de 2011, núm. 224, pp. 98872-98879.

España. Real Decreto 1393/2007, de 29 de octubre, por el que se establece la ordenación de las enseñanzas universitarias oficiales. Boletín Oficial del Estado, 30 de octubre de 2007, núm. 260, pp. 44037-44048.

España. Real Decreto Legislativo 1/2013, de 29 de noviembre, por el que se aprueba el Texto Refundido de la Ley General de derechos de las personas con discapacidad y de su inclusión social. Boletín Oficial del Estado, de 29 de noviembre de 2013, núm. 289, pp. 95635-95673.

European Telecommunications Standards Institute (ETSI) et al. (2018). Accessibility requirements suitable for public procurement of ICT products and services in Europe. EN 301549 V2.1.2 (2018-08). Sophia Antípolis: ETSI. Recuperado de https://www.etsi.org/deliver/etsi_en/301500_301599/301549/02.01.02_60/en_301549v020102p.pdf. 
Everett, S. y Oswald, G. (2018). "Engaging and training students in the development of inclusive learning materials for their peers". Teaching in Higher Education, 23(7), pp. 802-817. DOI: https://doi.org/10.1080/13562517.20 17.1421631.

Ferrer, M. D. et al. (2011). “¿Una sociedad de la información en igualdad de condiciones? Evaluación al grado de inclusión social-digital que ofrecen las TIC desde la perspectiva de la usabilidad y la accesibilidad". Quórum Académico, 8(2), pp. 247-267.

Fundación Universia (2018). Guía de atención a la discapacidad en la Universidad. Madrid: Fundación Universia. Recuperado de https://www.fundacionuniversia.net/wp-content/uploads/2018/12/GUIA_Atencion-a-la-discapacidad-2018_ACCESIBLE.pdf.

Garabal, J. (2015). "Universidad y diversidad funcional: aproximación a la inclusión en el ámbito universitario". Revista de Estudios e Investigación en Psicología de la Educación, 8, pp. 33-37. DOI: https://doi.org/10.17979/ reipe.2015.0.08.

García Pérez, M. y Ortega Sánchez, I. (2010). "Atención a la e-accesibilidad y usabilidad universal en el diseño formativo". Pixel-Bit. Revista de Medios y Educación, 36, pp. 89-99.

Garrison-Wade, D. F. (2012). "Listening to their voices: Factors that inhibit or enhance postsecondary outcomes for students' with disabilities”. International Journal of Special Education, 27(2), pp. 113-125.

González, A. P. y Farnós, D. (2009). “Usabilidad y accesibilidad para un e-learning inclusivo”. Revista Educación Inclusiva, 2(1), pp. 49-60.

Gutiérrez y Restrepo, E. y Martínez, L. (2010). “Localization and web accessibility”. Revista tradumática, 8, pp. 1-6. DOI: https://doi.org/10.5565/rev/tradumatica.106.

Hadjikakou, K. y Hartas, D. (2008). "Higher education provision for students with disabilities in Cyprus". Higher Education, 55(1), pp. 103-119. DOI: https://doi.org/10.1007/s10734-007-9070-8.

HEFCE (2002). Successful student diversity: Case studies of practice in learning and teaching and widening participation. Good Practice. Guidance for Senior Managers and Practitioners. Bristol: HEFCE. Recuperado de https://dera.ioe.ac.uk/11524/1/02_48.pdf.

Horton, S. y Leventhal, L. (2008). "Universal usability". En S. Harper e Y. Yesilada (eds.): Web Accessibility. Human-Computer Interaction Series. Londres: Springer.

Langørgen, E. y Magnus, E. (2018). "We are just ordinary people working hard to reach our goals! Disabled students' participation in Norwegian higher education". Disability \& Society, 33(4), pp. 598-617. DOI: https://doi. org/10.1080/09687599.2018.1436041.

Love, T. S. et al. (2015). "STEM Faculty experiences with students with disabilities at a land grant institution". Journal of Education and Training Studies, 3(1), pp. 27-38. DOI: https://doi.org/10.11114/jets.v3i1.573.

Moriña, A. (2018). "Learning from experience: training for faculty members on disability". Perspectives: Policy and Practice in Higher Education, 23(2), pp. 86-92. DOI: https://doi.org/10.1080/13603108.2018.1534759.

Moriña, A. et al. (2014). "Inclusive curricula in Spanish higher education? Students with disabilities speak out". Disability \& Society, 29(1), pp. 44-57. DOI: https://doi.org/10.1080/09687599.2013.769862.

Moriña, A. et al. (2015). "Students with disabilities in higher education: A biographical-narrative approach to the role of lecturers". Higher Education Research \& Development, 34(1), pp. 147-159. DOI: https://doi.org/10.108 0/07294360.2014.934329. 
Naciones Unidas (1948). Declaración Universal de Derechos Humanos. Recuperado de https://www.pillaro.gob. ec/wp-content/uploads/2018/09/DeclaraUDerHH.pdf.

Naciones Unidas (2006). Convención sobre los Derechos de las Personas con Discapacidad y Protocolo Facultativo. Recuperado de http://www.un.org/disabilities/documents/convention/convoptprot-s.pdf

Nganji, J. T. et al. (2011). "Ontology-based e-learning personalisation for disabled students in higher education". Innovation in Teaching and Learning in Information and Computer Sciences, 10(1), pp. 1-11. DOI: https://doi. org/10.11120/ital.2011.10010001.

Perera-Rodríguez, V. H. y Moriña Díez, A. (2019). "Technological challenges and students with disabilities in higher education”. Exceptionality, 27(1), pp. 65-76. DOI: https://doi.org/10.1080/09362835.2017.1409117.

Pliner, S. y Johnson, J. (2004). "Historical, theoretical, and foundational principles of universal instructional design in higher education". Equity \& Excellence in Education, 3, pp. 105-113. DOI: https://doi. org/10.1080/10665680490453913.

Powell, J. J. (2013). "From ableism to accessibility in the universal design university". The Review of Disability Studies: An International Journal, 8, pp. 33-45.

Preiser, W. F. y Smith, K. H. (2011). "Universal design at the urban scale”. En W. F. Preiser y K. H. Smith, Universal Design Handbook, $2^{\text {nd }}$ ed. (pp. 20.1-20.8). New York: Mcraw-Hill.

Sakız, H. y Sarıcal, M. (2017). "Including students with visual difficulty within higher education: Necessary steps". Exceptionality, 26(4), pp. 266-282. DOI: https://doi.org/10.1080/09362835.2017.1283627.

Seale, J. (2006). E-learning and disability in higher education: Accessibility research and practice. Abingdon, UK: Routledge.

Seale, J. (2017). "From the voice of a 'Socratic gadfly': A call for more academic activism in the researching of disability in postsecondary education". European Journal Of Special Needs Education, 32(1), pp. 153-169. DOI: https://doi.org/10.1080/08856257.2016.1254967.

Seale, J. et al. (2010): "Digital agility and digital decision-making: conceptualising digital inclusion in the context of disabled learners in higher education". Studies in Higher Education, 35(4), pp. 445-461. DOI: https://doi. org/10.1080/03075070903131628.

Seale, J. et al. (2015). "Not the right kind of 'digital capital'? An examination of the complex relationship between disabled students, their technologies and higher education institutions". Computers \& Education, 82, pp. 118128. DOI: https://doi.org/10.1016/j.compedu.2014.11.007.

UNESCO (1998). Conferencia Mundial sobre la Educación Superior en el siglo XXI: Visión y acción. Recuperado de https://unesdoc.unesco.org/ark:/48223/pf0000117022_spa.

Unterfrauner, E. y Weiermair-Märki, C. (2008). "E-accessibility in higher education institutions”. En J. Luca, J. y E. Weippl (eds.), Proceedings of ED-MEDIA 2008-World Conference on Educational Multimedia, Hypermedia \& Telecommunications (pp. 6220-6227). Viena: Association for the Advancement of Computing in Education (AACE).

Van Jaarsveldt, D. E. y Ndeya-Ndereya, C. N. (2015). “It's not my problem': exploring lecturers' distancing behaviour towards students with disabilities”. Disability \& Society, 30(2), pp. 199-212. DOI: https://doi.org/10.10 80/09687599.2014.994701.

Vieiro-Iglesias, P. et al. (2015). "Estrategias visuales para el manejo autónomo de TIC en discapacidad intelectual severa". Revista de Estudios e Investigación en Psicología y Educación, 13, pp. 033-037. DOI: https://doi. org/10.17979/reipe.2015.0.13.258. 
Vlachou, A. y Papananou, I. (2015). "Disabled students' narratives about their schooling experiences". Disability \& Society, 30(1), pp. 73-86. DOI: https://doi.org/10.1080/09687599.2014.982787.

Vlachou, A. y Papananou, I. (2018). "Experiences and Perspectives of Greek Higher Education Students with Disabilities”. Educational Research, 60(2), pp. 206-221. DOI: https://doi.org/10.1080/00131881.2018.1453752.

W3C (2018). Web Content Accessibility Guidelines (WCAG) 2.1. Recuperado de http://www.w3.org/TR/WCAG21/. 
Anexo 1. Planes de estudios analizados de las titulaciones ofertadas en el curso 2018-2019

- Universidad de Nebrija. Máster en Tecnologías de la Información y la Comunicación para la Educación y Aprendizaje Digital. Recuperado de https://www.nebrija.com/programas-postgrado/master/TIC-educacion./

- Universidad Católica de Valencia. Máster Universitario en Innovación Tecnológica en Educación. Recuperado de https://www.ucv.es/oferta-academica/posgrados/ciencias-de-la-educacion/master-universitario-en-innovacion-tecnologica-en-educacion.

- Universidad Internacional de Valencia. Máster Universitario en Educación, Tecnologías e Innovación. Recuperado de https://www.universidadviu.es/master-universitario-educacion-tecnologias-e-innovacion-tic/.

- Universidad Internacional de la Rioja. Máster Universitario en E-learning y Redes Sociales. Recuperado de https://www.unir.net/ingenieria/master-online-e-learning/549200001578/.

- Universidad de Salamanca. Máster Universitario en Las TICs en Educación: Análisis y Diseño de Procesos, Recursos y Prácticas Formativas. Recuperado de https://www.usal.es/master-tic-en-educacionanalisis-y-diseno-de-procesos-recursos-y-practicas-formativas.

- Universidad a Distancia de Madrid. Máster Universitario en Tecnología Educativa. Recuperado de https://www.udima.es/es/master-educacion-nuevas-tecnologias.html.

- Universidad de la Laguna. Máster Universitario en Educación y Tecnología de la Información y Comunicación. Recuperado de https://www.ull.es/masteres/educacion-tecnologia-informacion-comunicacion/.

- Universidad Autónoma de Madrid. Máster Universitario en Tecnologías de la Información y la Comunicación en Educación y Formación. Recuperado de http://www.uam.es/ss/Satellite/ es/1242670751438/1242662139792/masteroficial/masterOficia/Master_Universitario_en_Tecnologias_ de_la_Informacion_y_la_Comunicacion_en_Educacion_y_Formacion.htm.

- Universitat Oberta de Catalunya. Máster Universitario Educación y TIC (e-learning). Recuperado de https://estudios.uoc.edu/es/masters-universitarios/educacion-tic/presentacion.

- Universidad del País Vasco. Máster Universitario en Tecnología, Aprendizaje y Educación. Recuperado de https://www.ehu.eus/es/web/master/master-tecnologia-aprendizaje-educacion.

- Universidad Isabel I. Máster en Diseño Tecnopedagógico (e-learning). Recuperado de https://www.ui1. es/oferta-academica/master-en-diseno-tecnopedagogico/plan-de-estudios.

- Universidad de Extremadura. Máster Universitario en Educación digital. Recuperado de https://www. unex.es/organizacion/servicios-universitarios/servicios/servicio_becas/funciones/Masteres/masteresoficiales-fichas/master-universitario-en-educacion-digital.

- Universidad de Barcelona. Máster de entornos de enseñanza y aprendizaje mediados por tecnologías digitales. Recuperado de https://www.ub.edu/portal/documents/1042830/4548738/Plan_Estudios_ EEATD_2018-2019.pdf/c9b496b2-9196-1dba-baf3-bd15428228a6.

- Universidad de Sevilla. Máster e-learning: nuevas tecnologías para el aprendizaje a través de Internet. Recuperado de https://cfp.us.es/cursos/mu/e-learning-nuevas-tecnologias-para-el-aprendizaje-a-traves-de-internet $/ 5766 /$ ?basica $=1$.

- Universitat Rovira i Virgili (coordinadora), Universitat de les Illes Balears, Universitat de Lleida y Universidad de Murcia. Máster interuniversitario en Tecnología Educativa: e-Learning y Gestión del Conocimiento. Recuperado de http://www.urv.cat/es/estudios/masteres/oferta/tecnologia-educativa/. 